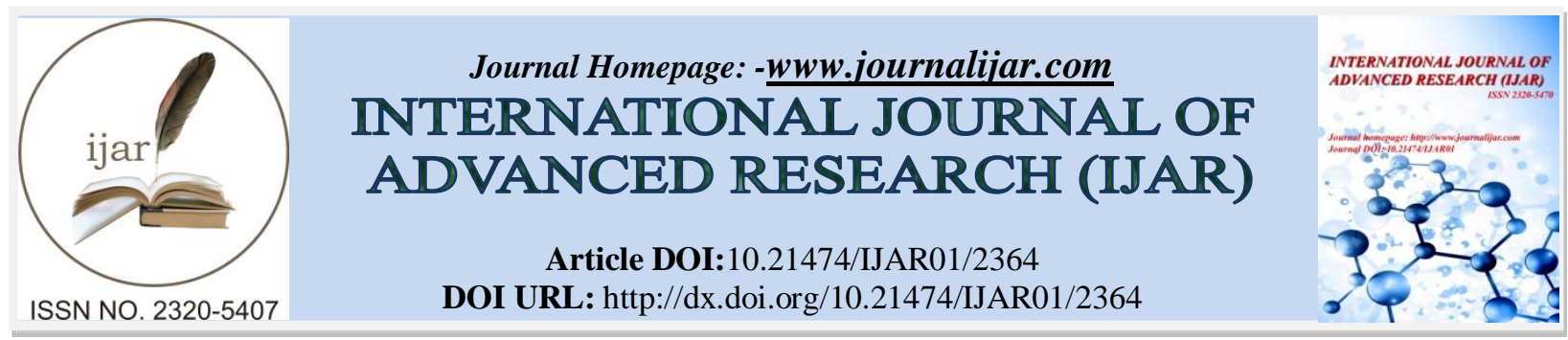

RESEARCH ARTICLE

\title{
INTERACTION OF INSTITUTIONS AND ENVIRONMENTAL DEGRADATION.
}

Cengiz Aytun ${ }^{1}$ and CemilSerhat Akin ${ }^{2}$.

1. Department of Finance-Banking and Insurance, Çukurova University, Adana, Turkey.

2. Department of Economics, Mustafa Kemal University, Hatay, Turkey.

\section{Manuscript Info}

Manuscript History

Received: 18 October 2016

Final Accepted: 20 November 2016

Published: December 2016

Key words:-

Institutional Quality, Environmental

Degradation, $\mathrm{CO}_{2}$ Emission, Panel Data

Analysis, Pollution Heaven Hypothesis

\section{Abstract}

Although there are many studies upon questioning the relation between the economic growth, energy consumption and environmental quality, the relationships between the institutional spheres in which the economic activities realize were not questioned adequately in those studies. To obtain sustainable development, institutions should be added to the analysis. To fill the gap, relationship between institutional quality and $\mathrm{CO}_{2}$ emissions was questioned in this study. The datum for 13 middle income countries which covers the period between the years from 2001 to 2011 was examined by the panel data analysis method. In the realized study, the Pollution Heaven Hypothesis was also examined. Variables which will represent the institutional quality level are taken as the subcomponents of World Governance Index. These variables are the control of corruption, the government effectiveness, political stability and the absence of violence/terrorism, the regulatory quality, the rule of law and voice and accountability. Per capita income, fossil fuel usage and energy consumption were used as an auxiliary explanatory variables in our model. Results support that institutional quality effect environmental quality directly and indirectly. The effects of the variables which used as indicators of institutional quality differ in the analysis.

Copy Right, IJAR, 2016,. All rights reserved.

\section{Introduction:-}

Although there are many studies upon questioning the relation between the economic growth, energy consumption and environmental quality, the relationships between the institutional spheres in which the economic activities realize were not questioned adequately in those studies. To obtain sustainable development, institutions should be added to the analysis. To fill the gap, relationship between institutional quality and $\mathrm{CO}_{2}$ emissions was questioned in this study. The datum for 13 middle-income countries which covers the period between the years from 2001 to 2011 , was examined by the panel data analysis method. In the study apart from the previous studies, the Pollution Heaven Hypothesis was also examined. Variables, which will represent the institutional quality level, are taken as the subcomponents of World Governance Index. These variables are the control of corruption, the government effectiveness, political stability and the absence of violence/terrorism, the regulatory quality, the rule of law and voice and accountability. Per capita income, fossil fuel usage and energy consumption were used as an auxiliary explanatory variable in our model. The rest of the paper is organized as follows. Section 2 summarizes related 
literature; Section 3 describes the variables and presents the empirical model. Section 4 presents the empirical findings of the study. Final section gives the conclusions and policy recommendations.

\section{The Literature Review:-}

There exists a growing literature which examines the causality relation between the energy consumption with economic growth and the institutional factors with $\mathrm{CO}_{2}$ emissions. Today, it has become important for policymakers to understand the causality relationship so that they could have designed the effective energy and environmental policies (Ozturk, 2010).

Brock and Taylor (2004) have evaluated the interaction between the environmental factors and economic activities on a base in which three ways of thinking exist. These are

- The effect of production scale

- The composition effect of produced assets

- The effect of production technique

\section{Scale Effect:-}

All economies in which the production scale was increased lead to the environmental degradation, however the increased production volume results in more need for energy. In particular, for under developed societies, the primary aim is to increase the amount of production. The increased production will put an incline for fuel consumption, and then this fuel consumption will also enhance the $\mathrm{CO}_{2}$ emissions, which result in environmental degradation.

\section{The Composition Effect:-}

In the early stages of development, countries produce the products, which are giving more damages to the environment. The level of social consciousness can only increase after a specific level of income. A clean environment can be perceived as one of the primary items of life quality after this stage. Along with the sanctions coming from civil society, the product composition can be oriented towards the less polluter products for environment. Only if the new composition of product was designed by paying attention on the environment, the environmental degradation could be decreased.

\section{The effect of technology:-}

Owing to the technological developments, the artificial products instead of natural resources can be produced, and then the environmental waste that was produced after production can be destroyed with less damage. Technological advancement and effective resource usage can decrease the environmental degradation.Lindmark also stated that the reason of the emergence of environmental-friendly technologies was highly related with the development of environmental consciousness and the foundling of the institution on this concept (Lindmark, 2002).

The main determiner of the direction of the relationship between the composition effect with technology effect and environmental mechanism is the institutions. The institutions can be defined as the common ways of thought, brought by societies, indeed they can also be inherited towards the next generations via cultural heritage (Stern, 2004). Institutions are the body of laws, which are about the life.

The effective using of institutions can prevent the serious increases in environmental degradation even at the early stages of economic development (Panayatou 1997). The existence of effective institutions decreases the environmental degradation mostly via the composition effect or by technology effect-mechanism. The internalization of environmental-friendly institutions by society can be effective on the determination of product composition. The durableness of institutions can support the technologic development and induce the investments.

Leitao (2010) analyzed the poverty levels of countries as the indicators of institutional quality for 41 countries, which are at different income levels, and then he questioned the relationship for environmental degradation. In his analysis, there was found a positive correlation between the emission of sulfur and poverty.

Tamazian and Rao (2010) performed a panel data analysis for 24 economies in transition benefiting from the datum for the years as 1993-2004, and found that the institutional quality was one of the determiners of environmental performance. 
Cole (2007) revealed the positive correlation between the level of poverty and the emission of $\mathrm{CO} 2$ and SO2. Schultz \& Crockett, (1990) and Payne (1995) established a relationship between institutional quality and political rights and the freedom of access to knowledge, and stated that increasing institutional quality would increase the environmental conscience, and this would prevent the environmental degradation.

Kumbaroğlu and his colleagues (2008) found in their analysis of Turkey, which was performed in order to determine the effects of financial freedom on environment, that the increase of financial freedom would give an opportunity for technological change, and new technologies could be more environmental-friendly, resulting in less damages for environment.

Panayatou (1993) also performed a panel data analysis for 30 countries and found in the societies where the institutional quality is high that no serious increases for environmental degradation could be observed even for the early stages of economic development.

Bhattari and Hammig (2001) performed panel data analysis for 66 Latin Africa and Asia countries, and found that there was relationship between the degradation of forests and the institutional quality of countries which exist in three different continents. As a result of the study, it was also found that less loss of forests occurred in the countries where the political institutions had been developed and the governments had been working effectively

Culas also conducted a panel data analysis in 2007 for 14 tropical countries and used the trustworthiness of property rights and policies created for environment. As a result of the study, it was also found that there was a negative relationship between institutional quality and environmental degradation

One of the branches of these strands which were executed in this movement is the interaction between foreign trade and environmental degradations. Indeed, two separate views exist in order to present the interaction between foreign trade and environmental degradation. One of them is the Pollution Heaven Hypothesis and the other one is technology transfers view. In the emerging economies, the demand for environmental quality is increasing via the growing income. The internalization of the negative externalities by the state via legal regulations also increases the costs of production. The firms which cause the environmental degradation generally transfer the production facilities towards to the undeveloped countries instead of institutional regulations. This mobility which called as Pollution Heaven Hypothesis can increase environmental degradation of the countries which have lower income level. On the other hand, the increase of trade openness can accelerate the capital inflow for new technologies via technology transfer and ease the facility of environment-friendly technologies. This situation can decrease the environmental deterioration in long term.

\section{Data and Empirical Methodology:-}

The data used in the application were obtained from World Bank (2016), the definitions and sources related to data are presented in Table 1.

Table 1:- Data Definitions and Sources.

\begin{tabular}{|c|l|c|}
\hline Code & Name & Source \\
\hline $\mathrm{CO}_{2}$ & CO2 emissions (metric tons per capita) & WDI $^{*}$ \\
\hline GDP & GDP per capita (constant 2005 US\$) & WDI $^{*}$ \\
\hline FOS & Fossil fuel energy consumption (\% of total) & WDI* $^{*}$ \\
\hline ELEC & Electric power consumption (kWh per capita) & WDI $^{*}$ \\
\hline FDI & Foreign direct investment, net inflows (\% of GDP) & WDI $^{*}$ \\
\hline RQ & Regulatory Quality & WDI $^{*}$ \\
\hline ROL & Rule of Law & WDI $^{*}$ \\
\hline GE & Government Effectiveness & WDI $^{*}$ \\
\hline PSAV & Political Stability and Absence of Violence/Terrorism & WDI $^{*}$ \\
\hline COR & Control of Corruption & WDI $^{*}$ \\
\hline VAC & Voice and Accountability & \\
\hline
\end{tabular}

The World Bank World Development Indicators: http://databank.worldbank.org

It will be useful to give information about the institutional determiners that will be included in the analysis. These are; 


\section{The quality of regulations:-}

This measures the regulations which are created by governments in order to produce efficient policies for the development of private sector and as well as their implementation.

The rule of law:-

It represents the feel of economic agents' confidence that will occur in the borders of social rules, and symbolizes the applicability of agreements, the property rights, the quality of police and judicial offices.

\section{The efficiency of government:-}

In addition to public services and civil services, it represents the governments' acting independently from political pressure, their policy production, implementation, and the credibility of governmental policies

\section{Political sustainability:-}

It represents the non-existence of political instability, the violence rooted from political reasons and/or the terrorist attacks

\section{The control of corruption:-}

It represents bringing the demands of interest groups and elitists upon the corrupt gains under control and measuring its prevention level.

\section{Freedom of speech and accountability:-}

It represents the free participation of citizens in the political groups, making themselves heard without pressure, and the existence of free press.

In the stage on determining the model to be included in model, the variables as per capita income fossil fuel usage electric consumption and foreign direct investment were added up each model under the framework of literature. Following this, the institutional indicators as Rule of Law, Government Effectiveness, Political Stability and Absence of Violence/Terrorism, Control of Corruption, Regulatory Quality Voice and Accountability were individually added up the model, and then their effects were questioned. As this transaction was conducted, it was also observed whether the signs of variables were changed or not, and then the soundness of the model was pursued.

MODEL 1: $\quad \operatorname{LCO}_{2 \mathrm{i}, \mathrm{t}}=\alpha_{\mathrm{i}}+\beta_{1} \mathrm{LGDP}_{\mathrm{i}, \mathrm{t}}+\beta_{2} \mathrm{LFOS}_{\mathrm{i}, \mathrm{t}}+\beta_{3} \mathrm{LELEC}_{\mathrm{i}, \mathrm{t}}+\beta_{4} \mathrm{LFDI}_{\mathrm{i}, \mathrm{t}}+\mathrm{v}_{\mathrm{t}}+\varepsilon_{\mathrm{i}, \mathrm{t}}$

MODEL 2: $\quad \operatorname{LCO}_{2 \mathrm{i}, \mathrm{t}}=\alpha_{\mathrm{i}}+\beta_{1} \mathrm{LGDP}_{\mathrm{i}, \mathrm{t}}+\beta_{2} \mathrm{LFOS}_{\mathrm{i}, \mathrm{t}}+\beta_{3} \mathrm{LELEC}_{\mathrm{i}, \mathrm{t}}+\beta_{4} \mathrm{LFDI}_{\mathrm{i}, \mathrm{t}}+\mathrm{LCOC}+\mathrm{v}_{\mathrm{t}}+\varepsilon_{\mathrm{i}, \mathrm{t}}$

MODEL 3: $\quad \operatorname{LCO}_{2 \mathrm{i}, \mathrm{t}}=\alpha_{\mathrm{i}}+\beta_{1} \mathrm{LGDP}_{\mathrm{i}, \mathrm{t}}+\beta_{2} \mathrm{LFOS}_{\mathrm{i}, \mathrm{t}}+\beta_{3}$ LELEC $_{\mathrm{i}, \mathrm{t}}+\beta_{4} \mathrm{LFDI}_{\mathrm{i}, \mathrm{t}}+\mathrm{LGE}_{\mathrm{i}}+\mathrm{v}_{\mathrm{t}}+\varepsilon_{\mathrm{i}, \mathrm{t}}$

MODEL 4: $\quad \operatorname{LCO}_{2 \mathrm{i}, \mathrm{t}}=\alpha_{\mathrm{i}}+\beta_{1} \mathrm{LGDP}_{\mathrm{i}, \mathrm{t}}+\beta_{2} \mathrm{LFOS}_{\mathrm{i}, \mathrm{t}}+\beta_{3} \mathrm{LELEC}_{\mathrm{i}, \mathrm{t}}+\beta_{4} \mathrm{LFDI}_{\mathrm{i}, \mathrm{t}}+\mathrm{LPS}+\mathrm{v}_{\mathrm{t}}+\varepsilon_{\mathrm{i}, \mathrm{t}}$

MODEL 5: $\quad$ LCO $_{2 \mathrm{i}, \mathrm{t}}=\alpha_{\mathrm{i}}+\beta_{1} \mathrm{LGDP}_{\mathrm{i}, \mathrm{t}}+\beta_{2} \mathrm{LFOS}_{\mathrm{i}, \mathrm{t}}+\beta_{3}$ LELEC $_{\mathrm{i}, \mathrm{t}}+\beta_{4} \mathrm{LFDI}_{\mathrm{i}, \mathrm{t}}+\mathrm{ROL}+\mathrm{v}_{\mathrm{t}}+\varepsilon_{\mathrm{i}, \mathrm{t}}$

MODEL 6: $\quad \operatorname{LCO}_{2 \mathrm{i}, \mathrm{t}}=\alpha_{\mathrm{i}}+\beta_{1} \mathrm{LGDP}_{\mathrm{i}, \mathrm{t}}+\beta_{2} \mathrm{LFOS}_{\mathrm{i}, \mathrm{t}}+\beta_{3} \mathrm{LELEC}_{\mathrm{i}, \mathrm{t}}+\beta_{4} \mathrm{LFDI}_{\mathrm{i}, \mathrm{t}}+\mathrm{RG}+\mathrm{v}_{\mathrm{t}}+\varepsilon_{\mathrm{i}, \mathrm{t}}$

MODEL 7:

$$
\mathrm{LCO}_{2 \mathrm{i}, \mathrm{t}}=\alpha_{\mathrm{i}}+\beta_{1} \mathrm{LGDP}_{\mathrm{i}, \mathrm{t}}+\beta_{2} \operatorname{LFOS}_{\mathrm{i}, \mathrm{t}}+\beta_{3} \mathrm{LELEC}_{\mathrm{i}, \mathrm{t}}+\beta_{4} \mathrm{LFDI}_{\mathrm{i}, \mathrm{t}}+\mathrm{VA}+\mathrm{v}_{\mathrm{t}}+\varepsilon_{\mathrm{i}, \mathrm{t}}
$$

In the models concerning the implementation index i refers to countries, index $t$ symbolizes time, $\alpha_{i}$ represents fixed country effects and $\mathrm{v}_{\mathrm{t}}$ indicates unobservable time effect, last $\varepsilon_{\mathrm{i}, \mathrm{t}}$ denotes the error term. The aim of the present study is to perform analyses considering 13 countries and five different income groups between the years from 2000 to 2013. All the variables are expressed in their natural logarithmic forms

Letter "L" which is used in front of variable symbols indicates that the logarithmic transformation was done to the related variable series. The most appropriate tool for the application, which offers various advantages by means of bringing together cross-sectional and time-series data consisting of different countries, is the panel data analysis. Simple linear panel data models can be estimated through basically three different methods. The first of these is the method which contains common constant. It is called as the pooled ordinary least squares method (POLS). The second one is the fixed effects model (FEM) which includes country and time effects as constant terms. The third one is the random effects model (REM) which includes country and time effects as random parameters rather than fixed ones. With the combination of the data on a panel, they can be estimated via various methods. Moreover; the process by which systematic differences are revealed by means of using dummy variables on panel data is called as fixed effects model. Another method is called as the random effects model (Asteriou \& Hall, 2007).

In the study for the purpose of making a selection among three basic estimators F test (Moulton \& Randolph, 1989), LM test (Breusch \& Pagan, 1980; Honda, 1985) and Hausman (1978) test were used. Presence of group specific 
effect $\left(\mathrm{H}_{0}: \alpha_{1}=\alpha_{2}=\ldots=\alpha_{\mathrm{n}}\right)$ is tested by $\mathrm{F}$ test. According to the null hypothesis, intercepts related to individuals are common. The method which can be applied in such homogeneity will be pooled OLS. When $\mathrm{H}_{0}$ is rejected, intercepts are considered different for each individual. The second essential tool in the model selection is the Breusch and Pagan (1980) Lagrange Multiplier test. In this test, the null hypothesis refers to the fact that the random effects variance between the individuals is zero $\left(\mathrm{H}_{0}: \sigma_{\mu}{ }^{2}=0\right)$. The failure in the rejection of the null hypothesis leads to the fact that the random effects between the individuals are not significant. However, the problem in this test is that alternative hypothesis is set up double-sided; however, the variance components are known to be positive. With a view to resolving such a problem, LM statistics was adapted by Honda (1985) to make the alternative hypothesis one-sided. As a result of the tests, pooled OLS estimator will be preferred in case of the absence of random panel effect. Moreover, between these two estimators, Hausman (1978) test is widely used on condition that fixed and random effects belonging to the individuals in F and LM tests are found to be significant. The main point to be mentioned in decomposing fixed and random effects methods is whether there is a correlation between such elements as individual as well as time and the explanatory variables in the model or not. The correlation of these elements with $\mathrm{X}_{\mathrm{it}}$ refers to the fixed effects model while the absence of this correlation reveals random effects model. $\mathrm{H}_{0}$ hypothesis follows: "there is not a correlation between the explanatory variables and individual effects". When zero hypothesis is accepted, both estimators will be consistent; nevertheless, as random effects estimator is more efficient, it will be appropriate to use it. In case of rejection of the hypothesis $\mathrm{H}_{0}$, as random effects estimator would be biased, the use of consistent fixed effects estimator would be appropriate. In addition, before using the appropriate estimator, the presence of autocorrelation and heteroscedasticity problems should be explored. In order to detect the autocorrelation in practice, Baltagi and Li (1995) LM statistic test and to detect heteroscedasticity, LM test statistics developed by Greene (2008) were used.

\section{Empirical Findings:-}

The statistical values of the selected F, LM, LM-Honda and Hausman estimator related to the all model are presented in the bottom panel of Table 2. According to the probability values of F-test, fixed effects estimator is significant at $1 \%$ for all models compared to the pooled OLS estimator. In this case, $\mathrm{H}_{0}$ hypothesis related to $\mathrm{F}$ test suggesting "fixed effects belonging to the models are equal" is rejected. On the other hand, according to the probability values of LM-test random effect estimator significant at the $1 \%$ for all models compared to the pooled OLS estimator. The fact that $\mathrm{H}_{0}$ hypothesis is rejected according to LM test random effects between the individuals is significant.

Table 2:-Model Choice and Diagnostic Test Results.

\begin{tabular}{|c|c|c|c|c|c|c|c|}
\hline & MODEL 1 & MODEL 2 & MODEL3 & MODEL 4 & MODEL5 & MODEL6 & MODEL7 \\
\hline F-group (fixed) & $261.3 * * *$ & $220.9 * * *$ & $251.4 * * *$ & $270 * * *$ & $200.4 * * *$ & $220.7 * * *$ & $261.17 * * *$ \\
\hline F-time (fixed) & $2.02 * *$ & $2.06 * *$ & $2.03 * *$ & $2.501 * *$ & $1.67 *$ & $2.19 * *$ & $1.7^{*}$ \\
\hline F-two-way (fixed) & $144.2 * * *$ & $119.98 * * *$ & $139.3 * * *$ & $148.7 * * *$ & $119.72 * * *$ & $126.2 * * *$ & $141.9 * * *$ \\
\hline LM-group (random) & $658.4 * * *$ & $616.7 * * *$ & $640 * * *$ & $607.6 * * *$ & $485.3 * * *$ & $530.4 * * *$ & $680.9 * * *$ \\
\hline LM-time (rand.) & 0,93 & 2,02 & 0,73 & 1,01 & 0,92 & 0,03 & 1,97 \\
\hline LM-two-way (rand.) & $659.3 * * *$ & $618.7 * * *$ & $640.8 * * *$ & $608.6 * * *$ & $486.2 * * *$ & $530.4 * * *$ & $682.9 * * *$ \\
\hline Honda-group (rand.) & $25.66 * * *$ & $24.83 * * *$ & $25.29 * * *$ & $24.65 * * *$ & $22.03 * * *$ & $23.03 * * *$ & $26.09 * * *$ \\
\hline Honda-time (rand.) & $-0,96$ & $-1,42$ & $-0,86$ & $-1,00$ & 0,96 & $-0,05$ & $-1,41$ \\
\hline Honda-two-way(rand.) & $17.46^{* * *}$ & $16.5^{* * *}$ & $17.28 * * *$ & $16.7 * * *$ & $16.2^{* * * *}$ & $16.24 * * *$ & $17.45 * * *$ \\
\hline Hausman & $9.55 * *$ & $11.51 * *$ & $9.311^{*}$ & $10.9^{* * *}$ & $16.24 * * *$ & $14.44 * *$ & $7.83 * *$ \\
\hline \multicolumn{8}{|l|}{ Heteroscedasticity tests } \\
\hline LMh (random) & $89.3^{* * *}$ & $84.1 * * *$ & $92.91 * * *$ & $111.4 * * *$ & $57.32 * * *$ & $83.01 * * *$ & $116.1 * * *$ \\
\hline LMh (fixed) & $28.01 * *$ & $29.15 * *$ & $27.47 * *$ & $38.1 * * *$ & $29.06 * * *$ & $29.73 * * *$ & $42.94 * * *$ \\
\hline \multicolumn{8}{|c|}{ Autocorrelation tests for fixed effect } \\
\hline LM-stat & $27.62 * * *$ & $27.5^{* * *}$ & $27.54 * * *$ & $25.42 * * *$ & $24.48 * * *$ & $27.72 * * *$ & $20.25 * * *$ \\
\hline Durbin-Watson & 0,99 & 0,99 & 0,99 & 1,03 & 1,01 & 0,99 & 1,13 \\
\hline \multicolumn{8}{|c|}{ Autocorrelation tests for random effect } \\
\hline LM-murho & $691.1 * * *$ & $645.4 * * *$ & $671 * * *$ & $637.9 * * *$ & $505 * * *$ & $551.03^{* * * *}$ & $726.3 * * *$ \\
\hline LM-mu|rho & $27.62 * * *$ & $617.8 * * *$ & $643.4 * * *$ & $612.4 * * *$ & $480.5 * * *$ & $523.31 * * *$ & $706.1 * * *$ \\
\hline LM-rho|mu & $32.70^{* * *}$ & $28.68 * * *$ & $30.96 * * *$ & $30.25 * * *$ & $19.64 * * *$ & $20.54 * * *$ & $45.43 * * *$ \\
\hline
\end{tabular}

Note: $* * * \mathrm{p}<0.01, * * \mathrm{p}<0.05, * \mathrm{p}<0.1$ 
In both tests, pooled OLS estimator is not preferred. After this stage, a preference is to be made between fixed and random effects. According to the probability value of Hausman tests, $\mathrm{H}_{0}$ hypothesis is rejected at for all model respectively 5\% (model 1),\%5 (model 2),\%10 (model 3), \%1 (model 4),\%1 (model 5) and \%5 (model 6), \%5 (model7) significance level. Therefore, consistent fixed effects are supposed to be used since random effects estimator is biased. According to the probability values, the most appropriate one is the fixed effects estimator. In short, according to the F, LM, LM-Honda and Hausman test preformed for all models the fixed effects estimator is preferred for all models. In addition, the results of the autocorrelation and heteroscedasticity tests which are carried out for both models shows that the problems mentioned arise for each model. Asymptotic t statistics cannot be used; instead, the "period white" method which was developed by White $(1980,1984)$ used in both models in order to obtain robust $\mathrm{t}$ statistics.

The results of the fixed effects estimation carried out for all models presented in Table 3 . The fixed effects estimation results performed for all models. When an overall assessment was done on the basis of income group in relation to the first model, it is evident that coefficients pertaining to the per capita income (LGDP) are positive and significant at $1 \%$ level for all models. $1 \%$ increase which is likely to occur in the LGDP leads to the increase Carbon dioxide emission $\left(\mathrm{LCO}_{2}\right), \% 0.716$ in model $1, \% 0.718$ in model 2, \% 0.819 in model, \% 0.718 in model 5 , \% 0.771 in model $6, \% 0.702$ in model 7.

Table-3:-Estimation Results.

\begin{tabular}{|c|c|c|c|c|c|c|c|}
\hline VARIABLES & MODEL 1 & MODEL 2 & MODEL 3 & MODEL 4 & MODEL 5 & MODEL 6 & MODEL 7 \\
\hline Dependent CO2 & (FE) & (FE) & (FE) & (FE) & (FE) & (FE) & (FE) \\
\hline \multirow[t]{2}{*}{ LGDP } & $0.716 * * *$ & $0.718 * * *$ & $0.718 * * *$ & $0.819 * * *$ & $0.718 * * *$ & $0.771 * * *$ & $0.702 * * *$ \\
\hline & $(7.007)$ & $(7.056)$ & $(6.955)$ & $(8.159)$ & $(6.219)$ & $(7.085)$ & $(7.236)$ \\
\hline \multirow[t]{2}{*}{ LFOS } & $1.77 * * *$ & $1.778 * * *$ & $1.779 * * *$ & $1.745 * * *$ & $1.772 * * *$ & $1.768 * * *$ & $1.765 * * *$ \\
\hline & $(9.635$ & $(9.66)$ & $(9.552)$ & $(10.09)$ & $(9.303)$ & $(9.668)$ & $(9.873)$ \\
\hline \multirow[t]{2}{*}{ LELEC } & $0.220 * * *$ & $0.233 * * *$ & $0.221 * * *$ & $0.227 * * *$ & $0.22 * * *$ & $0.205 * * *$ & $0.181 * * *$ \\
\hline & $(3.238)$ & $(3.256)$ & $(3.22)$ & $(3.579)$ & $(3.224)$ & $(3.006)$ & $(2.728)$ \\
\hline \multirow[t]{2}{*}{ LFDI } & -0.005 & $-0,005$ & $-0,005$ & $-0,008$ & $-0,005$ & $-0,004$ & 0,005 \\
\hline & $(-0.438)$ & $(-0.403)$ & $(-0.444)$ & $(-0.694)$ & $(-0.435)$ & $(-0.335)$ & $(0.458)$ \\
\hline \multirow[t]{2}{*}{$\mathrm{LCOC}$} & & $-0,046$ & & & & & \\
\hline & & $(-0.64)$ & & & & & \\
\hline \multirow[t]{2}{*}{ LGE } & & & $-0,018$ & & & & \\
\hline & & & $(-0.194)$ & & & & \\
\hline \multirow[t]{2}{*}{ LPS } & & & & $-0.203^{* * *}$ & & & \\
\hline & & & & $(-3.674)$ & & & \\
\hline \multirow[t]{2}{*}{ LROL } & & & & & $-0,002$ & & \\
\hline & & & & & $(-0.034)$ & & \\
\hline \multirow[t]{2}{*}{ LRQ } & & & & & & $-0,096$ & \\
\hline & & & & & & $(-1.379)$ & \\
\hline \multirow[t]{2}{*}{ LVA } & & & & & & & $-0.271 * * *$ \\
\hline & & & & & & & $(-2.821$ \\
\hline \multirow[t]{2}{*}{ Constant } & $-14.19 * * *$ & $-14.29 * * *$ & $-14.23 * * *$ & $-14.80 * * *$ & $-14.19 * * *$ & $-14.43 * * *$ & $-13.56 * * *$ \\
\hline & $(-10.58)$ & $(-10.56)$ & $(-10.45)$ & $(-11.63)$ & $(-10.42)$ & $(-10.73)$ & $(-10.33)$ \\
\hline Obs. & 156 & 156 & 156 & 156 & 156 & 156 & 156 \\
\hline Country num. & 13 & 13 & 13 & 13 & 13 & 13 & 13 \\
\hline$F$-statistics & 802.1 & 770.2 & 767.7 & 851.3 & 767.5 & 779.8 & 817.8 \\
\hline Adjusted R-Sq. & 0.992 & 0.992 & 0.992 & 0.993 & 0.992 & 0.992 & 0.993 \\
\hline
\end{tabular}

Note: $* * * \mathrm{p}<0.01, * * \mathrm{p}<0.05, * \mathrm{p}<0.1$ Standard errors are in parenthesis.

Furthermore, the significance and sign of the Fossil fuel usage (LFOS) are positive and significant at $1 \%$ level for all models. $1 \%$ increase which is likely to occur in the LFOS leads to the increase $\left(\mathrm{LCO}_{2}\right) \% 1.77$ in model $1, \% 1.778$ in model 2, \%1.779 in model 3, \% 1.745 in model 4, \% 1.772 in model 5, \%1.768 in model 6, \%1.765 in model 7.

Third control variable electric consumption (LELEC) coefficients are significant at $1 \%$ level also effect $\mathrm{LCO}_{2}$ positively for all models. $1 \%$ increase which is likely to occur in the LELEC leads to the increase $\left(\mathrm{LCO}_{2}\right) \% 0.220$ 
in model 1,0.233 \% in model 2, $0.221 \%$ in model 3, $0.227 \%$ in model $4,0.22 \%$ in model $5, \% 0.205$ in model 6 , $\% 0.181$ in model 7. Last control variable of foreign direct investment (LFDI) is insignificant for all model. As the control variables are evaluated together, there wasn't change sign of coefficient of institutional indicators which involved in the analysis. Those results also give us information about the robust characteristics of model.

When we add up the institutional quality variables to the model individually the Rule of Law (LROL) Government Effectiveness (LGE) Control of Corruption (LCOC), Regulatory Quality (RQ) Political Stability and Absence of Violence/Terrorism (LPS), Voice and Accountability (LVA) only (LPS) and (LVA) variables are significant. 1\% decrease of the LPS leads to the increase \% $0.203\left(\mathrm{LCO}_{2}\right)$. Similarly $1 \%$ decrease of the LVA leads to the increase $\%$ 0,271 increase $\left(\mathrm{LCO}_{2}\right)$. Based upon the estimation results, the significance and sign of the LGDP, LFOS, and LELEC variables is in accordance with the existing literature. It is obvious that the LPS and LCA have a negative impact on the $\mathrm{LCO}_{2}$.

\section{Discussion:-}

As the results obtained were evaluated, it can be obviously seen that the production had a negative effect on environmental degradation. This is also needed that the production methods in the countries which were included in the sample had to be reviewed in terms of environmental degradation. The energy consumption which was used in the production process has to be evaluated as well in order to question the effects of production on environment. Indeed, fossil fuels are the primary energy resources in the underdeveloped countries in order to gain an advantage about cost in production process. In particular, in the countries where the institutional regulations were not established, this option is preferred in order to gain the competitive edge. In the undeveloped countries, the policy makers aim firstly the increase of production, thence this results in the creation of macroeconomic policies in this direction, moreover the environmental quality has begun to be seen a luxury consumption good.

One of the results obtained in this study is that there exists a negative relationship between the political stability and environmental degradation. The emergence of political stability decreases the environmental degradation. This result can be derived from the demand of ingoing governments about production of their own policies instead of the successor policies. Indeed, the governments which came to power doesn't follow the policies of previous terms, and they criticize them via producing new policies in order to bring innovation. This case can result in the waste of resources and the loss of efficiency. The waves occurred in political processes also increase the environmental degradation. The political stability sustained in a country strengthen the institutions and this can decrease the environmental degradation.

Another result which was obtained in this study is that there also exists a negative relation between accountability and environmental degradation. The increase of accountability in a country will also make the producers more responsible. Transparency that can be taken as a rule, and this can abolish the black economy. In the societies where the accountability is high, the emergence of civil societies and non-governmental institutions as well as their organizing capability can be easier. In the societies where the environmental degradation is high, the supporting of nongovernmental organizations' establishment can be a good political tool in the struggle for environmental degradation.

Owing to NGOs, the communication in the society can be strengthened, the process as the transformation of existing rules towards common values will support the fighting spirit for environmental degradation. 


\section{References:-}

1. Asteriou, D.\& Hall, S. G., (2007). Applied Econometrics : A Modern Approach Using Eviews And Microfit. New York: Palgrave Macmillan.

2. Baltagi, B.H. \& Li, Q. (1991). A joint test for serial correlation and random individual effects, Statistics \& Probability Letters 11(3), 277-280

3. Bhattarai, M. \& Hamming, M. (2001). Institutions and the environment Kuznets curve for deforestation: across country analysis for Latin America, Africa and Asia. World Development 2001;29(6),995-1010.

4. Breusch, T. \& S., Pagan, A. R., (1980). The Lagrange Multiplier Test and its Applications to Model Specification in Econometrics. The Review of Economic Studies, 47(1), 239-253. Doi:10.2307/2297111

5. Brock W.,A.\& Taylor M. S.(2004). Economic Growth and the Environment: A Review Of Theory and Empirics NBER Working Paper Series, Working Paper no: 10854

6. Cole, M.,A. (2007). Corruption, income and the environment: an empirical analysis. Ecological Economics 62, 637-647.

7. Culas, R.,J. (2007). Deforestation and the environmental Kuznets curve: an institutional perspective. Ecological Economics 2007;61(2-3),429-37.

8. Greene, W., H. (2008). Econometric Analysis, 6th Ed., Upper Saddle River, N.J.Prentice Hall

9. Hausman, J., A. (1978). Specification Tests in Econometrics. Econometrica, 46(6), 1251-1271. Doi: $10.2307 / 1913827$

10. Honda, Y. (1985) Testing the error components model with non-normal disturbances, Review of Economic Studies, 52, 681-690

11. Kumbaroglu,G., Karali,N. \&Arikan,Y., (2008). CO2, GDP and RET: an aggregate economic equilibrium analysis for Turkey. Energy Policy 36,2694-2708.

12. Leitao, A. (2010). Corruption and the environmental Kuznets curve: empirical evidence for sulphur. Ecological Economics2010;69(11),2191-201.

13. Lindmark, M. (2002). An EKC-pattern in historical perspective: carbon dioxide emissions, technology, fuel prices and growth in Sweden. 1870-1997. Ecological Economics 42 (2002), 333-347

14. Moulton, B., R., \& Randolph, W., C. (1989). Alternative Tests of the Error Components Model. Econometrica, 57(3), 685-693. Doi:10.2307/1911059

15. Ozturk, I. (2010). Literature survey on energy-growth nexus. Energy Policy, 38(1), 340-9.

16. Ozturk, I.\&Acaravci, A. (2010). CO2 emissions, energy consumption and economic growth in Turkey. Renewable and Sustainable Energy Reviews 14, 3220-3225.

17. Panayotou, T. (1993), Empirical Tests and Policy Analysis of Environmental Degradation at Different Stages of Economic Development, In Technology, Environment, and Employment, Geneva: International Labour Office.

18. Panayotou, T. (1997). Demystifying the environmental Kuznets curve: Turning a black box into a policy tool. Environment and Development Economics;2(4),465-84.

19. Payne, R.,A. (1995). Freedom and the environment. Journal of Democracy 6, 41-55.

20. Schultz, C.B. \& Crockett, T.R., (1990). Economic development, democratization, and environmental protection in Eastern Europe. Boston College Environmental Affairs Law Review 18, 53-84.

21. Stern I., D. (2004), The Rise and Fall of the Environmental Kuznets Curve. World Development Vol. 32, No. 8, pp. 1419-1439, 2004

22. Tamazian, A. \& Rao, B.B., (2010). Do economic, financial and institutional developments matter for environmental degradation? Evidence from transitional economies. Energy Economics 32, 137-145.

23. WORLD BANK, 2016. World development indicators and global development finance. World Development Indicators. [Accessed 01 .07.2016]. Available from http://databank.worldbank.org/data/views/variableSelection/selectvariables.aspx?source. 